\title{
ИЗУЧЕНИЕ ЭФФЕКТА ГЕНОВ КОРОТКОСТЕБЕЛЬНОСТИ ПШЕНИЦЫ (Triticum aestivum L.) И РЖИ (Secale cereale L.) НА ПРИМЕРЕ РАСЩЕПЛЯЮЩЕЙСЯ ПОПУЛЯЦИИ ЯРОВОЙ ТРИТИКАЛЕ В УСЛОВИЯХ ВЕГЕТАЦИОННОГО ОПЫТА*
}

\author{
П.Ю. КРУПИН1, 2 , А.Г. ЧЕРНООК 1,2 , Г.И. КАРЛОВ1, 2, А.А. СОЛОВЬЕВ 1 , \\ А.Д. КОРШУНОВА르, М.Г. ДИВАШУК 1,2
}

\begin{abstract}
Интрогрессия генов короткостебельности считается одним из надежных приемов преодоления полегания у сортов тритикале. При этом снижение высоты растений тритикале может происходить под влиянием генов как пшеничного, так и ржаного происхождения. В нашей работе в геном яровой тритикале был перенесен ген ржаного происхождения $D d w 1$ и изучено влияние генов $D d w 1$ и $R h t-B 1 b$ на ряд хозяйственно значимых признаков. Мы получили семена $\mathrm{F}_{2}$ от скрещивания сортов озимой тритикале Авангард (Ddw1 Ddw1 Rht-B1a Rht-B1a) и яровой тритикале Соловей Харьковский (ddw1 ddw1 Rht-B1b Rht-B1b). Из них в условиях вегетационного опыта вырастили 273 растения с яровым типом развития (расщепляющаяся популяция $F_{2}$ ). У каждого растения индивидуально определяли высоту; число и длину междоузлий; длину, число колосков и плотность главного колоса; массу зерна, число зерен и массу 1000 зерен с главного колоса. Каждое изучаемое растение генотипировали по аллельному состоянию генов с использованием ПЦР маркеров: аллельное состояние Rht-B1 определяли с помощью комбинации праймеров BF, MR1 и WR1; аллельное состояние $D d w 1$ - с праймерами для микросателлитного локуса REMS1218, сцепленного с указанным геном. Для выявления механизма наследования изучаемых генов короткостебельности мы изучили их доминантные и аддитивные эффекты. При определении влияния алеллей короткостебельности на хозяйственно ценные признаки сравнивали между собой гомозиготы по аллелям дикого типа (ddw1 и Rht-B1a) и по аллелям короткостебельности (Ddw1 и Rht-B1b), рассматривая эффект каждого из генов (независимый анализ) и межлокусное взаимодействие. Статистическую значимость различий и ассоциаций между анализируемыми признаками и генотипом оценивали с помощью критерия $F$ Фишера, $U$-теста Манна-Уитни и коэффициента ранговой корреляции р Спирмена. Наши исследования показали, что эффекты интродуцированных генов $D d w 1$ и $R h t-B 1 b$ несколько отличаются от таковых у ржи и пшеницы. $D d w 1$ статистически значимо влиял на высоту растения (снижение достигало $40 \%, \mathrm{p}=0,05$ ), проявив себя как частично доминантный аллель. В присутствии Rht-B1b высота яровой тритикале тоже снижалась, но в меньшей степени, чем под воздействием гена $D d w 1$ (до $20 \%, \mathrm{p}=0,05)$, то есть аллель $R h t-B 1 b$ проявил себя как частично рецессивный. Наличие гена $R h t-B 1 b$ привело к увеличению массы зерна с колоса с 1,4 г до 1,7 г (на $21,4 \%, p=0,05)$ за счет повышения плотности колоса, большего числа колосков и возросшей фертильности. Интрогрессия гена Ddw1 вызывала снижение общей массы зерен с колоса с 1,8 г до 1,5 г (на 16,7 \%, p = 0,05) за счет уменьшения массы 1000 зерен с 45,7 г до 41,3 г (на 9,6 \%, p= 0,05). В целом оба изучаемых гена по влиянию на показатели зерновой продуктивности выступали антагонистами. Полученные результаты свидетельствуют о том, что у яровой тритикале сочетание двух генов короткостебельности - ржаного Ddw1 и пшеничного Rht-B1b формирует потенциал для повышения урожайности при создании низкостебельных форм и перспективно для селекции этой культуры.
\end{abstract}

Ключевые слова: яровая тритикале, Rht-B1b, Ddw1, структурный анализ, гены короткостебельности, ДНК маркеры, селекция.

Главной идеей при создании тритикале было комбинирование положительных признаков ржи Secale cereale L. (устойчивость к неблагоприятным условиям) и пшеницы Triticum aestivum L. (пригодность к разнообразному использованию в пищевой промышленности). Мировое производство тритикале сохраняет стабильный рост и достигло 15 млн т в 2016 году с общей площадью посевов 4,2 млн га (1), при этом культура имеет как фуражное, так и продовольственное значение $(2,3)$. К недостаткам тритикале, ограничивающим ее более широкое распространение при возделывании на зерно, относится полегание. Для борьбы с полеганием используют обработ-

* Работа выполнена при поддержке гранта РНФ № 17-76-20023. 
ку ретардантами, однако это удорожает продукцию и увеличивает химическую нагрузку на окружающую среду. Другой подход в решении этой проблемы - селекционное улучшение тритикале и создание сортов, устойчивых к полеганию. Выявлена высокая корреляция между устойчивостью растений тритикале к полеганию и высотой растения $(4,5)$. D. Losert c соавт. (5), проанализировав коллекцию из 199 озимых и 2 яровых тритикале, показали, что в результате селекции у тритикале в течение последних 30 лет наблюдается тренд существенного снижения высоты растений (на 0,38 см в год) и уменьшения склонности к полеганию, что обусловлено сильной взаимосвязью этих двух признаков (более короткие растения, как правило, устойчивее к полеганию) $(4,6)$.

Высота растения - сложный количественный признак $(7,8)$. У гексаплоидной тритикале (BBAARR), сочетающей геномы пшеницы (BBAA) и ржи (RR), укорочение растений может обеспечиваться генами пшеницы, ржи и/или их комбинацией.

В настоящее время у мягкой пшеницы выявлено 24 гена, снижающих высоту растения $(9,10)$. Наибольшее распространение в коммерческих сортах пшеницы получили гены $R h t-B 1 b(=R h t 1), R h t-D 1 b$ (=Rht2), $R h t-8 c, R h t-B l e(=R h t 11)$. Они действуют даже при высоких дозах удобрений и обладают плейотропным эффектом в отношении множества хозяйственно ценных признаков (11-13). У растений пшеницы в присутствии нечувствительных к гиббереллину генов короткостебельности Rht-Blb, Rht$D l b$, Rht-Ble высота снижается в среднем на 10-15\% по сравнению с таковой у носителей аллеля дикого типа $R h t-B l a$ (14-16). По влиянию на рост стебля эти гены проявляют себя как рецессивные или частично рецессивные. У ржи высота растения также контролируется множеством генетических факторов $(17,18)$. Уже известно 14 различных генов короткостебельности ржи (19-21), среди них три доминантных, из которых наибольшую селекционную ценность представляет ген $D d w 1$. В присутствие доминантного гена $D d w 1$ уменьшение высоты растений составляет до $40 \%$ у диплоидной и до $55 \%$ - у тетраплоидной ржи (22). Около $80 \%$ сортов ржи российской селекции созданы с использованием источников и доноров гена $D d w 1$, что позволило в среднем повысить урожайность озимой ржи на $12-15 \%$ (23). Ген $D d w 1$ был успешно перенесен в озимую тритикале (сорта Debo и Dalo) $(24,25)$, и с участием этого гена в Польше и Румынии получена серия низкостебельных сортов озимой тритикале $(26,27)$.

Различные гены короткостебельности пшеницы и ген короткостебельности ржи $D d w 1$ широко распространены среди коммерческих сортов озимой тритикале. У яровой тритикале гены короткостебельности задействованы не столь активно. Так, A.D. Korshunova coaвт. (28) в результате анализа 86 образцов яровой тритикале у 76 выявили ген $R h t-B 1 b$, причем все они относятся к коммерческим сортам. Однако ни у одного образца яровой тритикале не найден ген $D d w 1$. Таким образом, в настоящее время разнообразие генов короткостебельности у яровой тритикале крайне ограничено (28). Хромосомное замещение 2R/2D, которое также снижает высоту растений, в коммерческих сортах яровой тритикале не встречается $(29,30)$. Для пшеницы и озимой тритикале характерно большее разнообразие по генам короткостебельности, и в разных сортах снижение высоты обеспечивается различными генами или их сочетаниями. У яровой тритикале такого разнообразия не наблюдается, а целенаправленные работы по введению в ее геном других генов короткостебельности не проводились. Интрогрессии дополнительных генов короткостебельности из озимой тритикале и/или пшеницы в геномный пул яровой тритикале может помочь 
решить проблему высокорослости этой культуры и придать новый импульс ее развитию благодаря плейотропному действию генов короткостебельности на многие хозяйственно ценные признаки. При этом следует учитывать, что механизмы влияния генов короткостебельности на высоту растений сложны, оно, как правило, реализуются через вовлечение в различные пути ответа на фитогормоны (31) и зависит в том числе от дозы гена в геноме. Эффекты разных генов короткостебельности в геноме тритикале, где в результате межродового скрещивания сочетаются далекие друг от друга геномы, вызывают интерес в связи с познанием особенностей межлокусного взаимодействия генов и практическими задачами селекции и все еше исследованы недостаточно.

В настоящей работе мы показали, что у яровой тритикале эффекты генов короткостебельности ржаного происхождения $D d w 1$ и пшеничного происхождения $R h t-B 1 b$ несколько отличаются от таковых на ржи и пшенице. Изученные гены неодинаково влияли на высоту растений тритикале и выступали антагонистами по воздействию на элементы продуктивности.

Наша цель заключалась в оценке влияния генов $D d w 1$ и Rht-B1b и их взаимодействия на высоту растений и другие хозяйственно ценные признаки у яровой тритикале в условиях вегетационного опыта в расщепляющейся популяции $\mathrm{F}_{2}$.

Методика. В качестве родительских форм были выбраны сорта, несущие контрастные комбинации аллелей корокостебельности пшеницы и ржи, - сорт озимой тритикале Авангард (генотип Ddw1 Ddw1 Rht-Bla RhtBla; материнская форма) и сорт яровой тритикале Соловей Харьковский (генотип $d d w 1 d d w 1 R h t$-B1b Rht-B1b; отцовская форма). В 2014 году в теплице Центра молекулярной биотехнологии (РГАУ-МСХА им. К.А. Тимирязева) выращивали родительские растения, выполняли гибридизацию методом подстановки и получали растения $\mathrm{F}_{1}$. Семена материнского сорта Авангард высевали в вегетационные сосуды по 10 шт. В фазу кущения растения помещались в яровизационную комнату на 2 мес при $5{ }^{\circ} \mathrm{C}$. После прохождения яровизации (в фазу колошения) растения вновь перемещали в теплицу; на стадии лигулы колосья кастрировали и помещали под изолятор из пергаментной бумаги. Под изолятор также помещали колос срезанного отцовского растения в фазу цветения, стебель которого находился в сосуде с водой для поддержания жизнеспособности.

Семена поколения $\mathrm{F}_{2}$ высевали в вегетационные сосуды по 10 шт. и выращивали при одинаковых условиях освещения с дозированным поливом и внесением равных доз удобрений (теплица Центра молекулярной биотехнологии РГАУ-МСХА им. К.А. Тимирязева). В общей сложности получили 273 растения $\mathrm{F}_{2}$. Так как один из родительских сортов озимый, в расщепляющейся популяции $\mathrm{F}_{2}$ присутствовало некоторое количество озимых форм, которые выбраковали по фенотипу.

Каждое растение индивидуально анализировали по следующим признакам: высота, число междоузлий, длина каждого междоузлия, длина главного колоса (ДК), число зерен с главного колоса (ЧЗ), число колосков на главном колосе, масса зерен с главного колоса (М3). Также рассчитывали плотность колоса (ПК) и массу 1000 зерен (М1000) по формулам соответственно [1] и [2]:

$$
\begin{aligned}
\Pi К & =\frac{}{2 К} 10, \\
\mathrm{M}_{1000} & =\frac{\mathrm{M} 3}{\mathrm{ч3}} 1000 .
\end{aligned}
$$

Для каждого растения $\mathrm{F}_{2}$ индивидуально устанавливали аллельное 
состояние генов $D d w 1$ и $R h t-B 1$ с помощью молекулярных маркеров.

Геномную ДНК, используемую для оценки гибридности и генотипа по аллелям анализируемых генов выделяли из каждого вегетирующего растения $\mathrm{F}_{1}$ и $\mathrm{F}_{2} \mathrm{CTAB}$ методом (32).

Аллельное состояние генов $R h t-B 1$ и $D d w 1$ у растений $\mathrm{F}_{1}$ и $\mathrm{F}_{2}$ определяли с помощью ПЦР с использованием молекулярных маркеров (синтез праймеров выполнен в ООО «Синтол», Россия). Для выявления аллелей Rht-Bla (дикий тип) и Rht-B1b использовали праймеры BF, MR1 и WR1; ПЦР осуществляли в соответствии с условиями, рекомендованными для этих целей авторами молекулярного маркера (33). Продукты ПЦР разделяли в $2 \%$ агарозном геле в буфере ТВЕ и окрашивали бромистым этидием для последующей визуализации в УФ-трансиллюминаторе. Использовали маркер молекулярных масс GeneRuler 100 bp DNA Ladder («Thermo Fisher Scientific», США). Наличие гена $D d w 1$ определяли с помощью праймеров для амплификации последовательности микросателлитного локуса REMS1218, тесно сцепленного с этим геном (34). Аллели микросателлита REMS1218 определяли при помощи ПЦР согласно протоколу, описанному авторами молекулярного маркера, с последующим анализом фрагментов (генетический анализатор 3130xl Genetic Analyzer, «Applied Biosystems», США). Доминантная гомозигота $D d w 1 D d w 1$ выявляется в виде двух фрагментов размером 317 п.н. и 321 п.н. при одинаковой высоте пиков, гетерозигота $D d w 1 d d w 1$ - как два фрагмента с разной высотой пиков: 317 п.н. (высокий) и 321 п.н. (низкий), у рецессивной гомозиготы $d d w 1 d d w 1$ выявляется один фрагмент размером 317 п.н.

Схему наследования определяли на основе оценки генетических эффектов согласно методике, изложенной А.В. Смиряевым и А.В. Кильчевским (35). Рассчитывали аддитивный (a) и доминантный (d) эффекты относительно среднего по всей популяции. При $\mathrm{d}=0$ схема наследования аддитивная; если $\mathrm{d}=\mathrm{a}$, то аллель доминантный, если $\mathrm{d}=-\mathrm{a}-$ аллель рецессивный; если $0<|\mathrm{d}|<|\mathrm{a}|$, то аллель частично доминантный (при одинаковом знаке d и а) или частично рецессивный (при разных знаках $d$ и a); если $|\mathrm{d}|>|\mathrm{a}|$, то гетерозигота проявляет сверхдоминирование по анализируемому признаку (гетерозис).

Влияние аллелей короткостебельности на изучаемые признаки определяли на основе сравнения их проявления у гомозиготы по аллелю короткостебельности и гомозиготы по аллелю дикого типа двумя способами. Для оценки эффектов каждого из генов в отдельности (независимый анализ) сопоставляли средние по популяции показатели у гомозигот только по гену пшеничного происхождения (Rht-Bla или $R h t-B 1 b)$ без учета влияния ржаного генотипа или у гомозигот только по ржаному гену ( $D d w 1$ или $d d w l)$ без учета пшеничного генотипа. При втором способе учитывали совместный эффект ржаного $(D d w 1)$ и пшеничного (Rht-B1) генотипов, определяя влияние пшеничного гена в зависимости от аллельного состояния ржаного гена и наоборот (межлокусное взаимодействие).

Для каждого количественного признака проводили проверку на нормальность распределения с помощью $W$-теста Шапиро-Уилка. Для каждой из непрерывных величин определяли среднее арифметическое $(M)$ и стандартное отклонение $( \pm \mathrm{SD})$. Значимость различий между показателями у гомозигот с аллелями дикого типа $(d d w 1$ или Rht-Bla) и с аллелями короткостебельности $(D d w 1$ или $R h t-B 1 b)$ определяли на основе следующих критериев. Для оценки различий между двумя группами использовали непараметрический $U$-критерий Манна-Уитни. Для выявления связей между сопоставляемыми показателями применяли метод рангового корреляцион- 
ного анализа $\rho$ Спирмена. Различия, при которых $\mathrm{p} \leq 0,05$, рассматривали как статистически значимые. Для выявления значимости различий между средними проводили дисперсионный анализ и использовали критерий наименьшей существенной разницы на $5 \%$ уровне значимости $(\mathrm{p}=0,05$; $\left.\mathrm{HCP}_{05}\right)$. Статистический анализ данных выполняли с применением пакета программ Statistica 10.0 («StatSoft Inc.», США).

Результаты. Для определения схемы наследуемости и влияния генов короткостебельности на хозяйственно ценные признаки яровой тритикале в условиях вегетационного опыта мы использовали семена поколения $\mathrm{F}_{2}$ от скрещивания сортов озимой тритикале Авангард (генотип $D d w 1 D d w 1 R h t-B 1 a R h t-B 1 a)$ и яровой тритикале Соловей Харьковский (генотип $d d w 1 d d w 1 R h t-B 1 b R h t-B 1 b)$. Сорт Авангард сочетает высокую продуктивность зерна с устойчивостью к полеганию и высокой зимо- и морозостойкостью, хорошие хлебопекарные качества (36-38). Вторая родительская форма - сорт Соловей Харьковский рекомендуется для производства продовольственного, технического и фуражного зерна, обладает хорошими хлебопекарными свойствами, соломина имеет оптимальную высоту (95110 см), крепкая, устойчивая к полеганию (39).

$\mathrm{y}$ каждого растения $\mathrm{F}_{2}$ определили генотип (аллельное состояние генов короткостебельности) (рис.) и проанализировали основные хозяйственно ценные признаки.

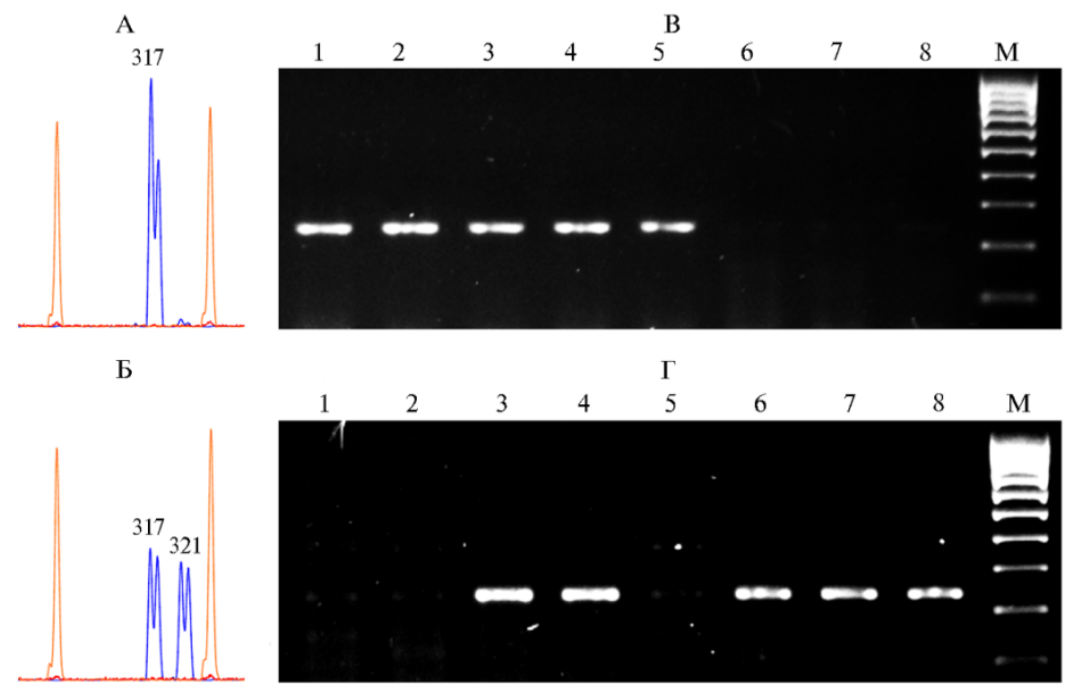

Определение аллельного состояния генов Ddw1 (слева, а и б) и Rht-B1 (справа, в и г) у растений $\mathbf{F}_{2}$ яровой тритикале (сорт Авангард $\times$ сорт Соловей Харьковский). Слева представлена электрофореграмма продуктов амплификации с использованием праймеров для микросателлитного локуса REMS1218 (фрагментный анализ): а - гомозигота по аллелю $d d w 1$, размер фрагмента 317 п.н.; б - гомозигота по аллелю $D d w 1$, размеры фрагментов 317 п.н. и 321 п.н. Справа представлена электрофореграмма продуктов амплификации с праймерами BF + WR1 (в, идентификация аллеля Rht-B1a,237 п.н.) и BF + MR1 (г, идентификация аллеля Rht-B1b, 237 п.н.): 1, 2, 5 - гомозиготы Rht-Bla Rht-Bla; 6, 7, 8 - гомозиготы Rht-Blb Rht-B1b; 3, 4 гетерозиготы Rht-B1a Rht-B1b; М - маркер молекулярной массы (GeneRuler 100 bp DNA Ladder («Thermo Fisher Scientific», США).

Высота растений. Результаты проведенного статистического анализа показывают, что $D d w 1$ обладает неполным доминированием у тритикале, а $R h t-B 1 b$ - частично рецессивный аллель; оба гена существенно влияют на высоту растений у яровой тритикале в условиях вегетационного опыта (табл. 1).

Анализ схемы наследования на основе выявления аддитивных и 
доминантных эффектов генов $D d w 1$ и $R h t-B 1 b$ показал, что у яровой тритикале в полученной расщепляющейся популяции $\mathrm{F}_{2}$ аллель короткостебельности $D d w 1$ обладает аддитивным эффектом в случае снижения высоты в среднем на 20,9 см и доминантным - при снижении на 11,7 см $(\mathrm{d}<\mathrm{a})$. Гомо- и гетерозиготы по аллелю $D d w 1$ статистически значимо различались $(\mathrm{p}=0,05)$. То есть по общему влиянию на высоту растения этот аллель проявляет неполное доминирование. Аллель $R h t-B 1 b$ оказался частично рецессивным: его аддитивный эффект составлял $-7,1$ см при доминантном эффекте $+2,3$ см $(0<|\mathrm{d}|<|\mathrm{a}|)$ (гомо- и гетерозиготы $R h t-B 1 b$ без $D d w 1$ различаются существенно, $\mathrm{p}=0,05)$. В литературе аллель $R h t-B 1 b$ также описан как частично рецессивный (40-43).

1. Статистический анализ влияния генов $R h t-B 1, D d w 1$ и их взаимодействия на высоту растений в расщепляющейся популящии гибрида $F_{2}$ яровой тритикале (сорт Авангард $\times$ сорт Соловей Харьковский; вегетационный опыт)

\begin{tabular}{|c|c|c|c|c|c|}
\hline \multirow{3}{*}{$\begin{array}{l}\text { Генотип по } \\
\text { аллелям } D d w 1\end{array}$} & \multirow{3}{*}{ Высота, см } & \multicolumn{3}{|c|}{ Генотип по аллелям Rht-B1 } & \multirow{3}{*}{$\begin{array}{l}\text { Разница между } \\
\text { гомозиготами } \\
\text { по } R h t-B 1 b \text { и } \\
R h t-B 1 a, \text { см }\end{array}$} \\
\hline & & \multicolumn{3}{|c|}{ Rht-B1b Rht-B1b|Rht-B1a Rht-B1b|Rht-B1a Rht-B1c } & \\
\hline & & \multicolumn{3}{|c|}{ высота, см } & \\
\hline & & $88,4 \pm 22,2^{\mathrm{a} ~} \S$ & $92,6 \pm 23,6^{\mathrm{a}} \S$ & $97,5 \pm 30,9^{b} \S$ & $-9,1^{*}(-9,3 \%)$ \\
\hline$D d w 1 D d w 1$ & $76,3 \pm 13,8^{\mathrm{a}} \S$ & $74,7 \pm 13,7$ & $77,9 \pm 14,2$ & $75,3 \pm 13,9$ & $-0,6(-0,8 \%)$ \\
\hline$D d w 1 d d w 1$ & $84,3 \pm 18,7 \mathrm{a} \S$ & $84,5 \pm 19,6$ & $84,3 \pm 16,1$ & $84,0 \pm 22,0$ & \\
\hline$d d w 1 d d w 1$ & $116,3 \pm 23,5^{b} \S$ & $102,8 \pm 23,0$ & $118,6 \pm 19,4$ & $130,8 \pm 20,1$ & $-28,0^{*}(-21,4 \%)$ \\
\hline \multicolumn{6}{|l|}{ Разница между } \\
\hline$D d w 1$ и $d d w 1$, см & $-40,0 *(-34,4 \%)$ & $-28,1^{*}(-27,3 \%)$ & & $-55,5^{*}(-42,4 \%)$ & \\
\hline \multicolumn{6}{|c|}{$\begin{array}{l}\text { П р и м е ч а н и е. В таблице указаны средние значения со стандартным отклонением }(M \pm \mathrm{SD}) ; \S-\text { резуль- } \\
\text { таты независимого анализа эффекта аллелей; } F(D d w l)=111,2>F_{0,05}=3,0 ; F(R h t-B I)=5,0>F_{0,05}=3,0 \text {; } \\
F(D d w 1 \times R h t-B I)=5,2>F_{0,05}=2,4 \text {. } \\
\text { * Различия между гомозиготами существенны на } 95 \% \text { уровне доверительной вероятности }(\mathrm{p}=0,05) \text {. } \\
\text { Одинаковыми буквами обозначены средние значения, выявленные при независимом анализе по каждому } \\
\text { из генов и не различающиеся на } 95 \% \text { уровне доверительной вероятности }(\mathrm{p}=0,05) \text {. }\end{array}$} \\
\hline
\end{tabular}

При анализе эффекта аллеля $R h t-B 1 b$ без учета влияния гена $D d w 1$ (см. табл. 1) разница между гомозиготами Rht-B1b Rht-B1b и Rht-Bla Rht-B1a оказалась статистически значимой и составила 9 см, или 9,1\% (p=0,05). Независимый анализ эффекта $D d w 1$ также выявил, что гомозиготы $D d w 1 D d w 1$ и $d d w 1 d d w 1$ статистически значимо различались по высоте растений (в среднем на 40 см, или $34,4 \%, \mathrm{p}=0,05$ ).

При изучении межлокусного взаимодействия разница между гомозиготами $R h t-B 1 b R h t-B 1 b$ и Rht-Bla Rht-B1a в отсутствие аллеля $D d w 1$ также оказалась значимой и составила 28 см, или $21,0 \%(\mathrm{p}=0,05)$ (см. табл. 1). Снижение высоты растений у мягкой пшеницы с аллелем Rht-Blb по сравнению с носителями аллеля дикого типа Rht-Bla, по данным литературы, может составлять до $17 \%(42,44)$. В присутствии аллеля $D d w 1$ различия между гомо- и гетерозиготами по алеллю $R h t-B 1 b$ были статистически несущественными, что, вероятно, объясняется маскирующим эффектом гена $D d w 1$, то есть снижение высоты за счет $D d w 1$ значительно превышает таковое вследствие присутствия Rht-B1b.

Разница по высоте между растениями-гомозиготами $D d w 1 D d w 1$ и $d d w 1 d d w 1$, не несущими $R h t-B 1 b$ пшеницы, была значима (p $=0,05)$ и составляла $-55,5$ см $(-42,4 \%)$, а с несущими аллель $R h t-B 1 b--28,1$ см $(-27,3 \%)$ (см. табл. 1). Уменьшение разницы между гомозиготами по $D d w 1$ в зависимости от наличия $R h t-B l b$ можно объяснить тем, что во втором случае ген $D d w 1$ снижает высоту растений, у которых высота уже снижена благодаря $R h t-B 1 b$. Различия между гомозиготами $D d w 1 D d w 1$ с аллелем и без аллеля $R h t-B 1 b$ статистически незначима. По имеющимся сообщениям (22), снижение высоты растений ржи за счет аллеля $D d w 1$ 
составляет от 40 до $55 \%$.

По полученным нами в вегетационном опыте данным, у яровой тритикале при статистическом анализе независимо по каждому из изучаемых генов короткостебельности наблюдаются эффекты, схожие с эффектами этих генов у пшеницы и ржи. В геноме яровой тритикале эффект ржаного гена короткостебельности $D d w 1$ значительно сильнее эффекта пшеничного гена короткостебельности $R h t-B 1 b$. Однако при этом отсутствует кумулятивный эффект по снижению высоты растений от совместного присутствия двух генов. В то же время у пшеницы, по данным литературы $(45,46)$, при совместном присутствии генов короткостебельности $R h t-B 1 b$ и $R h t-D 1 b$ или $R h t-B 1 b / R h t-B 1 e / R h t-D 1 b$ и Rht-8 высота снижается значительно сильнее, чем под влиянием только одного из генов. Таким образом, если цель селекционного процесса будет заключаться в снижении высоты растения у тритикале, то сочетание двух генов короткостебельности $(D d w 1$ и $R h t-B 1 b)$ вряд ли окажется более эффективным, чем интрогрессия одного из генов. При этом следует учитывать, что введение в геном гена $D d w 1$ у яровой тритикале позволит в большей степени снизить высоту растений, чем использование гена $R h t$ - Blb, распространенного в настоящее время среди коммерческих сортов данной культуры.

Число и длина междоузлий. При независимом анализе мы не выявили влияния пшеничного гена $R h t-B l b$ на число и длину междоузлий в популяции яровой тритикале. Наличие ржаного аллеля $D d w 1$ независимо от аллельного состояния пшеничного гена $R h t-B 1$ статистически значимо $(\mathrm{p}=0,05)$ снижает число междоузлий в среднем на 0,2 междоузлия; достоверное снижение длины за счет $D d w 1$ наблюдалось по всем междоузлиям, при этом наиболее сильное - по верхнему 1-му и 2-му междоузлиям (соответственно на 32,7 и 37,5 \%, $\mathrm{p}=0,05$, табл. 2).

При анализе межлокусного взаимодействия в изучаемой расщепляющейся популяции $\mathrm{F}_{2}$ мы не обнаружили эффекта алелля $R h t-B 1 b$ у в отношении числа междоузлий как в присутствии, так и в отсутствие аллеля $D d w 1$. Так как аллель $D d w 1$ маскирует влияние $R h t-B 1 b$ на высоту растения у яровой тритикале, то последствия присутствия аллеля Rht-Blb на изменение длины междоузлий мы изучили только у растений, не несущих аллель $D d w 1$ (см. табл. 2). Статистически значимое снижение длины за счет $R h t-B 1 b$ произошло по 1-му верхнему междоузлию и составило 9,5 cм $(-22,0 \%, \mathrm{p}=0,05)$. По всем междоузлиям отмечали общую тенденцию по уменьшению длины за счет $R h t-B 1 b$. Согласно опубликованным данным, в разных популяциях пшеницы высота междоузлий из-за присутствия Rht$B 1 b$ уменьшается неодинаково. Так, W. Liu c соавт. (4) сообщают о распределении по междоузлиям 17, 21 и 24 \% (соответственно 1-е, 2-е и 3-е сверху), у Y.G. Нu (47) распределение по междоузлиям составило 23, 14 и $28 \%$. По данным литературы $(4,47)$ и результатам, полученным в нашей работе, наибольший вклад в снижение высоты растений в присутствии Rht$B 1 b$ обеспечивается за счет уменышения длины именно 1-го междоузлия.

Анализ межлокусного взаимодействия показал, что в отсутствие пшеничного аллеля короткостебельности $R h t-B 1 b$ 1-е верхнее междоузлие укорачивается под воздействием аллеля $D d w 1$ в среднем на 18,5 см (42,0 \%), а в присутствии аллеля $R h t-B 1 b-$ на 10,6 см (30,0\%); в обоих вариантах статистически значимое снижение высоты $(\mathrm{p}=0,05)$ наблюдали по трем верхним междоузлиям (см. табл. 2). Зависимость влияния $D d w 1$ на длину междоузлий от наличия/отсутствия $R h t-B 1 b$ связано с тем, что в присутст- 
2. Статистический анализ влияния генов $R h t-B 1, D d w 1$ и их взаимодействия на длину междоузлий растений в расщепляющейся популящии гибрида $\mathbf{F}_{2}$ яровой тритикале (сорт Авангард $\times$ сорт Соловей Харьковский; вегетационный опыт)

\begin{tabular}{|c|c|c|c|c|c|c|c|c|c|c|c|c|c|c|c|c|}
\hline \multirow{2}{*}{ Генотип } & \multicolumn{4}{|c|}{$R h t-B 1$ в отсутствие $D d w 1$} & \multicolumn{4}{|c|}{$D d w 1 \S$} & \multicolumn{4}{|c|}{$D d w 1$ в отсутствие $R h t-B 1 b$} & \multicolumn{4}{|c|}{$D d w 1$ в присутствии Rht-B1b } \\
\hline & 1HMY & 3ВMУ & 2BMY & 1BMY & 1НMУ§ & 3ВMУ§ & 2BMУ§ & 1BMУ§ & 1HMY & 3ВМУ & 2BMУ & 1BMY & 1HMУ & 3ВМУ & 2BMУ & 1BMY \\
\hline 2 & & & & $34,7 \pm 8,7^{\mathrm{a}}$ & & & & & & & & & & & & \\
\hline 1 & & & & & & & & & & & & & & & & \\
\hline 0 & $7,0 \pm 3,8^{a}$ & $18,2 \pm 3,6^{\mathrm{a}}$ & $32,6 \pm 6,5^{\mathrm{a}}$ & $44,2 \pm 10,0^{\mathrm{a}}$ & $5,9 \pm 3,6^{\mathrm{a}}$ & $17,8 \pm 4,3^{\mathrm{a}}$ & $28,5 \pm 6,3^{\mathrm{a}}$ & $39,8 \pm 9,9^{a}$ & $7,0 \pm 3,8$ & & $31,0 \pm 6,5$ & $44,4 \pm 10,0$ & $5,3 \pm 3,8^{\mathrm{a}}$ & $16,30 \pm 4,2^{\mathrm{a}}$ & & $35,1 \pm 8,7 \mathrm{a}$ \\
\hline $\begin{array}{l}\text { омозиготами, } \\
\text { м (\%) }\end{array}$ & $\begin{array}{c}-1,7 \\
-23,0 \%)\end{array}$ & $\begin{array}{l}-2,0 \\
-10,0 \%)\end{array}$ & $\begin{array}{l}-5,2 \\
-16,0 \%)\end{array}$ & $\begin{array}{c}-9,5^{*} \\
(-22,0 \%)\end{array}$ & $\begin{array}{c}1,1^{*} \\
(18,6 \%)\end{array}$ & $\begin{array}{c}5,3^{*} \\
(29,6 \%)\end{array}$ & $\begin{array}{c}10,7^{*} \\
(37,5 \%)\end{array}$ & $\begin{array}{c}13,0^{*} \\
(32,7 \%)\end{array}$ & $\begin{array}{c}-1,6 \\
(23,0 \%)\end{array}$ & $\begin{array}{c}5,6^{*} \\
(31,0 \%)\end{array}$ & $\begin{array}{c}-13,0^{*} \\
(42,0 \%)\end{array}$ & $\begin{array}{c}-18,5^{*} \\
(42,0 \%)\end{array}$ & $\begin{array}{c}-1,3 \\
25,0 \%)\end{array}$ & $\begin{array}{c}-3,7^{*} \\
(23,0 \%)\end{array}$ & $\begin{array}{c}-9,8^{*} \\
(38,0 \%)\end{array}$ & $\begin{array}{c}-10,6^{*} \\
(30,0 \%)\end{array}$ \\
\hline
\end{tabular}

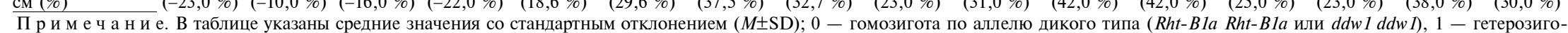

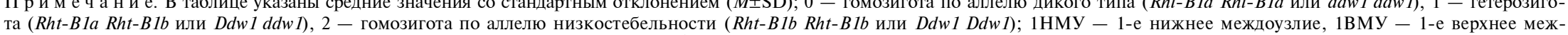

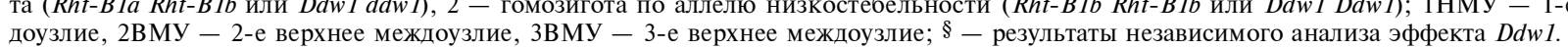

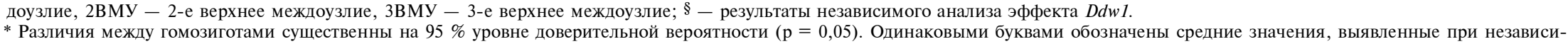
мом анализе по каждому из генов (или их комбинаций) по каждому из междоузлий и не различающиеся на $95 \%$ уровне доверительной вероятности (р $=0,05)$. 
вии $R h t-B 1 b$ 1-е междоузлие уже укорочено из-за эффекта пшеничного гена низкостебельности.

Длина колоса. Аллель $R h t-B 1 b$ не показал достоверного влияния на длину колоса. При независимом анализе влияния ржаного гена короткостебельности $D d w 1$ на длину колоса с использованием непараметрического $U$-критерия Манна-Уитни (распределение отклонялось от нормального) были выявлены статистически значимые различия (на уровне значимости $\mathrm{p}=0,04)$. Также при применении рангового корреляционного анализа Спирмена была выявлена статистически значимая корреляция между длиной колоса и наличием в геноме растения $D d w 1(\rho=-0,15 ; \mathrm{p}=0,05)$. Таким образом, в условиях вегетационного опыта наличие ржаного гена $D d w 1$ статистически значимо снижало длину колоса в среднем на 1 см.

Мы не выявили статистически значимого влияния межлокусного взаимодействия двух генов на длину главного колоса у яровой тритикале в изученной расщепляющейся популяции $\mathrm{F}_{2}$. Средняя длина колоса у растений без генов короткостебельности составляла 10,3 см, с геном $D d w 1-$ 9,3 см, с геном Rht-Blb-8,9 см, с двумя генами - 9,5 см (табл. 3).

Число колосков. Статистически значимого влияния двух изученных генов на число колосков главного колоса у яровой тритикале в исследованной расщепляющейся популяции $\mathrm{F}_{2}$ мы не выявили ни при независимом анализе, ни при анализе межлокусного взаимодействия (см. табл. 3), но можно отметить определенную тенденцию в изменении этого признака. Так, пшеничный ген короткостебельности $R h t-B 1 b$ при наличии гена короткостебельности ржи $D d w 1$ увеличивал число колосков в главном колосе, а в отсутствие ржаного гена наблюдался обратный эффект (см. табл. 3).

Плотность колоса. При независимом анализе генов (см. табл. 3) мы установили статистически значимое влияние гена $R h t-B 1 b$ ( $U$-критерий Манна-Уитни, $\mathrm{p}=0,02$ ) на увеличение плотности колоса. При применении метода рангового корреляционного анализа Спирмена также была выявлена статистически значимая корреляция $(\rho=0,19, \mathrm{p}=0,05)$. Увеличение плотности колоса в этом случае происходит за счет увеличения числа колосков. Аллель $D d w 1$ при независимом анализе статистически достоверного влияния на плотность колоса у яровой тритикале не проявил. Вероятно, это связано с однонаправленностью тенденций по снижению как длины колоса, так и числа колосков. Статистически значимого взаимодействия генов по этому показателю у яровой тритикале в расщепляющейся популяции $\mathrm{F}_{2}$ мы тоже не выявили.

Число зерен с главного колоса. Анализ схемы наследования гена $R h t-B 1$ показал его достоверное аддитивное влияние на число зерен в главном колосе $(+3,3$ зерна, или 9,2 \%, $\mathrm{p}=0,05)$, при этом аллель $R h t-B 1 b$ проявлял себя как доминантный, то есть гомо- и гетерозиготы по Rht-Blb значимо не различались (см. табл. 3). Эти данные сопоставимы с влиянием гена Rht-Blb на число зерен у мягкой пшеницы. Так, показано, что этот ген увеличивает число колосков, их фертильность, а в итоге и число зерен у мягкой пшеницы $(42,44,48,49)$.

Влияния гена $D d w 1$ на число зерен с главного колоса мы не обнаружили, хотя и наблюдали тенденцию к снижению этого показателя в отсутствие аллеля короткостебельности $R h t-B 1 b$. Статистически значимого влияния взаимодействия двух генов на число зерен с главного колоса у яровой тритикале в расщепляющейся популяции $\mathrm{F}_{2}$ мы также не отмечали (см. табл. 3).

Масса зерен с главного колоса. При независимом анализе 
эффектов по каждому гену в отдельности в условиях вегетационного опыта нами выявлены следующие закономерности (см. табл. 3). Наличие пшеничного аллеля короткостебельности Rht-B1b приводило к статистически значимому увеличению массы зерна с главного колоса ( $U$-критерий МаннаУитни $\mathrm{p}=0,04)$ с 1,4 до 1,7 г (на 21,4 \%). При этом наблюдается достоверная корреляция между этими параметрами $(r=0,15 ; \mathrm{p}=0,05)$. Наличие ржаного гена короткостебельности $D d w 1$ статистически значимо уменьшало массу зерна с главного колоса ( $U$-критерий Манна-Уитни $\mathrm{p}=0,02)$ с 1,8 до 1,5 г (на 16,7 \%) при $r=-0,18(\mathrm{p}=0,05)$.

3. Статистический анализ влияния генов $R h t-B 1, D d w 1$ и их взаимодействия на характеристики колоса и зерна в расщепляющейся популяции гибрида $\mathbf{F}_{2}$ яровой тритикале $(M \pm \mathrm{SD}$; сорт Авангард $\times$ сорт Соловей Харьковский; вегетационный опыт)

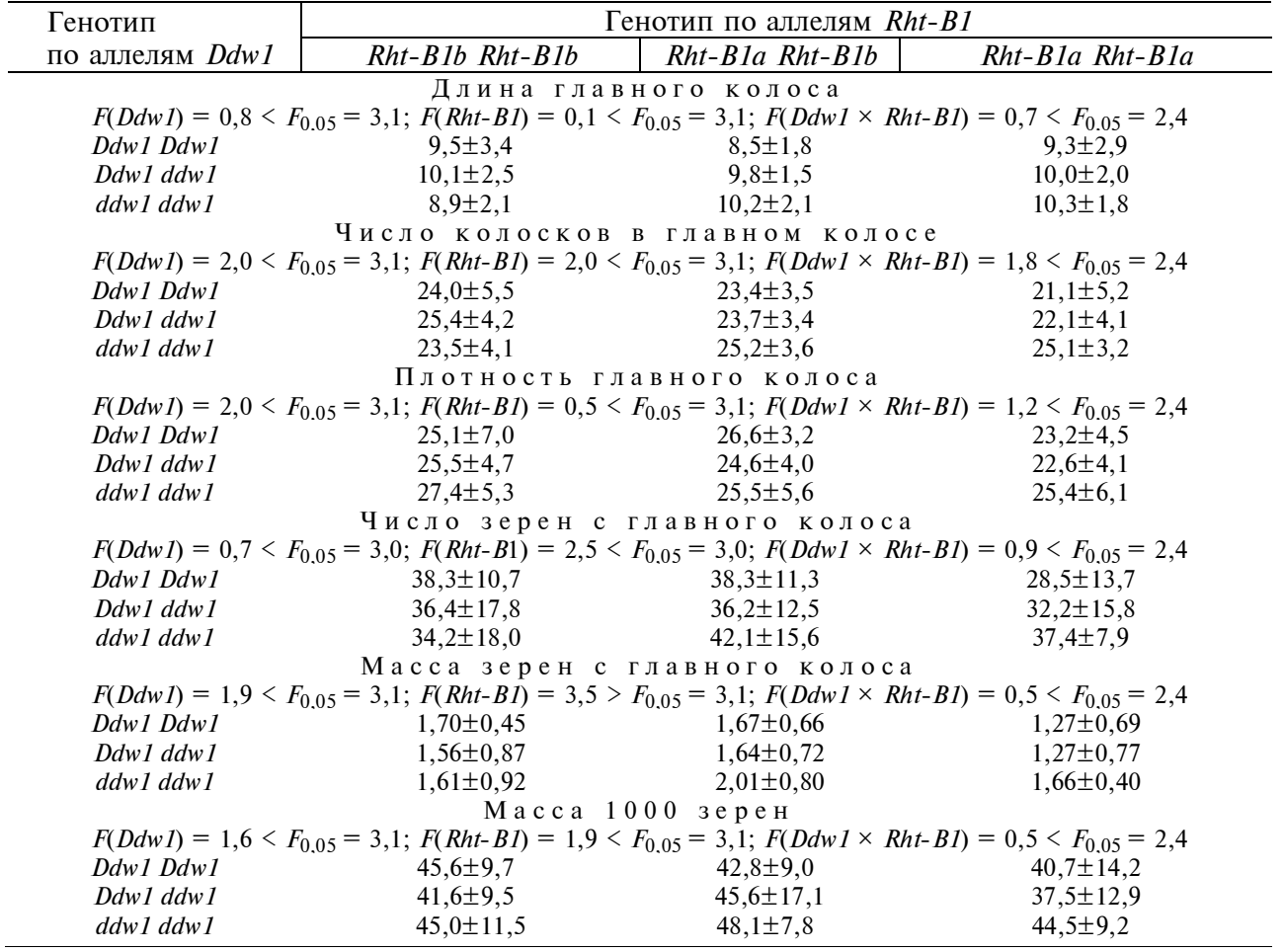

При изучении межлокусного взаимодействия в популяции статистически значимый доминантный эффект аллеля Rht-Blb в отношении массы зерна с главного колоса составил $+0,28$ г $(16,0 \%)$, то есть этот аллель повышает массу зерен с главного колоса в гетерозиготах (см. табл. 3). Статистически значимых различий при взаимодействии двух генов не выявили, но прослеживалась тенденция к увеличению массы зерна с колоса в присутствии $R h t-B 1 b$ и к уменьшению - в присутствии $D d w 1$. В целом можно говорить о тенденции взаимной компенсации эффектов генов в изучаемой расщепляющейся популяции яровой тритикале по анализируемому признаку (снижение массы зерна с колоса под влиянием гена $D d w 1$ и увеличение - под воздействием гена $R h t-B 1 b)$.

Масса 1000 зерен. При анализе изучаемой расщепляющейся популяции $\mathrm{F}_{2}$ по каждому гену в отдельности (см. табл. 3) оказалось, что наличие пшеничного аллеля короткостебельности $R h t-B l b$ не оказывает статистически значимого влияния на массу 1000 зерен. Наличие ржаного гена короткостебельности $D d w 1$ статистически значимо уменьшало массу 
1000 зерен с главного колоса ( $U$-критерий Манна-Уитни р $=0,02)$ с 45,7 до 41,3 г (на 9,6 \%) в условиях вегетационного опыта. При этом между анализируемыми параметрами наблюдалась статистически значимая корреляция $r=-0,17$ ( $\mathrm{p}=0,05)$. Следовательно, общее снижение массы зерна с главного колоса в присутствии ржаного гена короткостебельности $D d w 1$ обусловлено прежде всего снижением массы зерновок, а не уменьшением их числа. При анализе схемы наследования мы обнаружили незначительный доминантный эффект гена $R h t-B 1 b$ в отношении массы 1000 зерен, что выражается в повышении показателя у гетерозигот в среднем на 4,2 г $(10,1 \%)$. Незначительный аддитивный эффект аллеля $D d w 1$ заключался в снижении массы 1000 зерен в среднем на 2,0 г (4,5 \%), при этом Ddw1 проявлял себя как доминантный аллель, проявляясь в гомо- и гетерозиготах.

Эти и остальные выявленные нами закономерности требуют дополнительного изучения на других популяциях яровой тритикале, а также в полевом опыте.

Итак, наши исследования, выполненные в условиях вегетационного опыта на расщепляющейся популяции гибрида $F_{2}$ яровой тритикале, показали, что эффекты генов короткостебельности ржаного происхождения $D d w 1$ и пшеничного происхождения $R h t-B 1 b$ несколько отличаются от таковых на ржи и пшенице. Ген $D d w 1$ оказал достоверное влияние на высоту растения (ее уменьшение достигало 40 \%). Но при этом наблюдались и потенциально негативные эффекты, которые могут отразиться на урожайности яровой тритикале. Наличие гена $D d w 1$ привело к снижению общей массы зерна с колоса за счет уменьшения массы 1000 зерен. При этом ген $D d w 1$, который у ржи увеличивает размер колоса и озерненность колосков, в нашем опыте на яровой тритикале такого эффекта не проявил. Ген Rht-B1b тоже снижал высоту растений яровой тритикале, но значительно слабее, чем ген $D d w 1$ (до $20 \%$ ), и вовсе не влиял на этот признак в присутствии гена $D d w 1$. В то же время наличие гена $R h t-B 1 b$ повысило массу зерна с колоса за счет увеличения плотности колоса, числа колосков и повышения фертильности. В целом изучаемые гены короткостебельности ( $D d w 1$ ржаного происхождения и $R h t$-Blb - пшеничного) по влиянию на параметры зерновой продуктивности выступали антагонистами. Однако их сочетание у яровой тритикале, хотя и не приводит к дополнительному снижению высоты растений относительно гомозигот по $D d w 1$, перспективно для селекции, так как формирует потенциал для увеличения урожайности за счет создания низкостебельных форм.

\footnotetext{
1ФГБНУ Всероссийский НИИ сельскохозяйственной биотехнологии,

127550 Россия, г. Москва, ул. Тимирязевская, 42,

e-mail: pavelkroupin1985@gmail.com, irbis-sibri@ya.ru, karlov@iab.ac.ru, a.soloviev70@gmail.com,divashuk@gmail.com;

2ФГБОУ ВПО Российский государственный

аграрный университет-МСХА им. К.А. Тимирязева,

127550 Россия, г. Москва, ул. Тимирязевская, 49,

e-mail: korshunova.ad88@gmail.com
}

Sel'skokhozyaistvennaya biologiya [Agricultural Biology], 2019, V. 54, № 5, pp. 920-933

Поступила в редакцию 25 апреля 2018 года

\title{
EFFECTS OF DWARFING WHEAT (Triticum aestivum L.) AND RYE (Secale cereale L.) GENES IN SPRING TRITICALE SEGREGATING POPULATION AS STUDIED IN POT TRIALS
}

\author{
P.Yu. Kroupin1, 2, A.G. Chernook ${ }^{1,2}$, G.I. Karlov', 2, A.A. Solov'ev'1, \\ A.D. Korshunova ${ }^{2}$, M.G. Divashuk, 2
}


${ }^{1}$ All-Russian Research Institute of Agricultural Biotechnology, 42, ul. Timiryazevskaya, Moscow, 127550 Russia, e-mail pavelkroupin1985@gmail.com ( $₫$ corresponding author), irbis-sibri@ya.ru, karlov@iab.ac.ru, a.soloviev70@gmail.com, divashuk@gmail.com;

2Timiryazev Russian State Agrarian University-Moscow Agrarian Academy, 49, ul. Timiryazevskaya, Moscow, 127550 Russia, e-mail korshunova.ad88@gmail.com

ORCID:

Kroupin P.Yu. orcid.org/0000-0001-6858-3941

Chernook A.G. orcid.org/0000-0002-8793-1742

Karlov G.I. orcid.org/0000-0002-9016-103X

Solov'ev A.A. orcid.org/0000-0003-4480-8776

The authors declare no conflict of interests

Korshunova A.D. orci.dorg/0000-0002-8651-8286

Acknowledgements:

Supported financially by Russian Science Foundation (grant No. 17-76-20023)

Received April 25, 2018

doi: 10.15389 /agrobiology.2019.5.920eng

\section{Abstract}

The urgent problem of triticale lodging may be reliably overcome by introgression of dwarfing genes into triticale cultivars. Notable, both wheat and rye dwarfing genes can reduce the height of triticale plants. Therefore, a single contribution of various dwarfing genes and their additive effects in triticale which is an intergeneric hybrid still remain intriguing in fundamental aspects and important for breeding practice. In our study, rye dwarfing gene $D d w 1$ has been transferred into spring triticale. Then we have hybridized winter triticale cv. Avanguard ( $D d w 1 D d w 1$ Rht-B1a Rht-B1a) with spring triticale cv. Solovei Kharkovskii ( $d d w 1 d d w 1 R h t-B 1 b R h t-B 1 b)$ and used $F_{2}$ seeds to reveal the mechanism of inheritance of the studied dwarfing genes $D d w 1$ and $R h t-B 1 b$ and to determine the effect of the dwarfing alleles on economically valuable traits in the segregating population of spring triticale. Under the greenhouse conditions, 273 plants of the spring type of the segregating population $F_{2}$ were grown to individually estimate plant height, the number and length of internodes, spikelet length and number per spike, spike density, grain weight, grain number and 1000-grain weight per the main spike. Each plant was also genotyped by PCR using the markers of the $D d w 1$ and $R h t-B 1$ allelic state. To investigate inheritance patterns, the dominant and additive effects of genes were calculated. The second task was achieved by comparing plants homozygous for wild-type alleles $(d d w 1$ and $R h t-B 1 a)$ and short-stem alleles $(D d w 1$ and $R h t-B 1 b)$ with estimation of both independent effect of each genes and their interlocus interaction. Using statistical methods (Fisher F-criterion, Mann-Whitney $U$-test, and Spearman rank correlation coefficient $\rho$ ), we found the significance of the differences and associations between phenotypic traits and genotype. Our studies have shown that the effects of the $D d w 1$ and $R h t-B 1 b$ are somewhat different from those in wheat. The $D d w 1$ statistically significant affects plant height (by reducing up to $40 \%, \mathrm{p}=0.05$ ), manifesting itself as a partially dominant allele. The $R h t-B 1 b$ results in a decrease in the spring triticale plant height but less than the $D d w 1$ gene does (only up to $20 \%, \mathrm{p}=0.05$ ). Hence, the $R h t-B 1 b$ allele is proven to be partially recessive. In the presence of gene $R h t-B 1 b$ a kernel weight increases from $1.4 \mathrm{~g}$ to $1.7 \mathrm{~g}$ (by $21.4 \%)$ due to higher spike density and fertility. The $D d w 1$ gene introgression leads to a $16.7 \%$ decrease $(\mathrm{p}=0.05)$ in the total grain weight per spike (from $1.8 \mathrm{~g}$ to $1.5 \mathrm{~g}$ ) due to a $9.6 \%$ decrease $(\mathrm{p}=0.05$ ) in the 1000 -grain weight (from $45.7 \mathrm{~g}$ до $41.3 \mathrm{~g}$ ). In general, the $D d w 1$ and $R h t$-B $1 b$ genes affect the studied traits as antagonists. In summary, a combination of two dwarfing genes, $D d w 1$ from rye and $R h t-B 1 b$ from wheat, makes it possible to maximize yield of dwarf spring triticale plants and is promising for breeding. ers, breeding.

Keywords: spring triticale, $R h t-B 1 b, D d w 1$, structural analysis, dwarfing genes, DNA mark-

\section{RE F E R E N C ES}

1. FAOSTAT. Data. Available http://www.fao.org/faostat/en/\#data. Accessed 20.04.2018.

2. Goryanina T.A. Izvestiya Orenburgskogo gosudarstvennogo agrarnogo universiteta, 2017, 5(67): 4244 (in Russ.).

3. McGoverin C.M., Snyders F., Muller N., Botes W., Fox G., Manley M. A review of triticale uses and the effect of growth environment on grain quality. Journal of the Science of Food and Agriculture, 2011, 91(7): 1155-1165 (doi: 10.1002/jsfa.4338).

4. Liu W., Leiser W.L., Maurer H.P., Li J., Weissmann S., Hahn V., Würschum T. Evaluation of genomic approaches for marker-based improvement of lodging tolerance in triticale. Plant Breeding, 2015, 134(4): 416-422 (doi: 10.1111/pbr.12284).

5. Losert D., Maurer H.P., Marulanda J.J., Würschum T. Phenotypic and genotypic analyses of diversity and breeding progress in European triticale $(\times$ Triticosecale Wittmack). Plant Breeding, 2017, 136(1): 18-27 (doi: 10.1111/pbr.12433).

6. Navabi A., Iqbal M., Strenzke K., Spaner D. The relationship between lodging and plant height in a diverse wheat population. Canadian Journal of Plant Science, 2006, 86(3): 723-726 (doi: 10.4141/p05-144).

7. Würschum T., Liu W., Busemeyer L., Tucker M., Reif J., Weissmann E., Hahn V., Ruckel- 
shausen A., Maurer H. Mapping dynamic QTL for plant height in triticale. BMC Genetics, 2014, 15(1): 59 (doi: 10.1186/1471-2156-15-59).

8. Miedaner T., Hübner M., Korzun V., Schmiedchen B., Bauer E., Haseneyer G., Wilde P., Reif J.C. Genetic architecture of complex agronomic traits examined in two testcross populations of rye (Secale cereale L.). BMC Genomics, 2012, 13(1): 706 (doi: 10.1186/1471-2164-13-706).

9. McIntosh R.A., Yamazaki Y., Dubcovsky J., Rogers J., Morris C., Appels R., Xia X.C. Catalogue of gene symbols for wheat, 2013. Available https://shigen.nig.ac.jp/wheat/komugi/genes/macgene/2013/GeneSymbol.pdf. Accessed 20.04.2018.

10. McIntosh R.A., Dubcovsky J., Rogers W.J., Morris C., Xia X.C. Catalogue of gene symbols for wheat, 2017. Available https://shigen.nig.ac.jp/wheat/komugi/genes/macgene/supplement2017.pdf. Accessed 20.04.2018.

11. Mo Y., Vanzetti L., Hale I., Spagnolo E., Guidobaldi F., Al-Oboudi J., Odle N., Pearce S., Helguera M., Dubcovsky J. Identification and characterization of Rht25, a locus on chromosome arm 6AS affecting wheat plant height, heading time, and spike development. Theoretical and Applied Genetics, 2018, 131(10): 2021-2035 (doi: 10.1007/s00122-018-3130-6).

12. Jobson E., Martin J., Schneider T., Giroux M. The impact of the Rht-B1b, Rht-D1b, and Rht-8 wheat semi-dwarfing genes on flour milling, baking, and micronutrients. Cereal Chemistry, 2018, 95(6): 770-778 (doi: 10.1002/cche.10091).

13. Zhao K., Xiao J., Liu Y., Chen S., Yuan C., Cao A., You F., Yang D., An S., Wang H., Wang X. Rht23 (5Dq') likely encodes a $Q$ homeologue with pleiotropic effects on plant height and spike compactness. Theoretical and Applied Genetics, 2018, 131(9): 1825-1834 (doi: 10.1007/s00122-018-3115-5).

14. Rebetzke G.J., Bonnett D.G., Ellis M.H. Combining gibberellic acid-sensitive and insensitive dwarfing genes in breeding of higher-yielding, sesqui-dwarf wheats. Field Crops Research, 2012, 127: 17-25 (doi: 10.1016/j.fcr.2011.11.003).

15. Divashuk M., Vasilyev A., Bespalova L., Karlov G. Identity of the Rht-11 and Rht-Ble reduced plant height genes. Russian Journal of Genetics, 2012, 48(7): 761-763 (doi: 10.1134/S1022795412050055).

16. Divashuk M.G., Fesenko I.A., Karlov G.I., Bespalova L.A., Vasilyev A.V., Puzyrnaya O.Y. Reduced height genes and their importance in winter wheat cultivars grown in southern Russia. Euphytica, 2013, 190(1): 137-144 (doi: 10.1007/s10681-012-0789-7).

17. Mahone G.S., Frisch M., Bauer E., Haseneyer G., Miedaner T., Falke K.C. Detection of donor effects in a rye introgression population with genome-wide prediction. Plant Breeding, 2015, 134(4): 406-415 (doi: 10.1111/pbr.12283).

18. Alheit K., Busemeyer L., Liu W., Maurer H., Gowda M., Hahn V., Weissmann S., Ruckelshausen A., Reif J., Würschum T. Multiple-line cross QTL mapping for biomass yield and plant height in triticale ( $\times$ Triticosecale Wittmack). Theoretical and Applied Genetics, 2013, 127(1): 251-260 (doi: 10.1007/s00122-013-2214-6).

19. Börner A., Plaschke J., Korzun V., Worland A. The relationships between the dwarfing genes of wheat and rye. Euphytica, 1996, 89(1): 69-75 (doi: 10.1007/bf00015721).

20. Kobylyanskii V.D. Materialy II Vavilovskoi mezhdunarodnoi konferentsii «Geneticheskie resursy kul'turnykh rastenii v XXI veke. Sostoyanie, problemy, perspektivy» [Proc. II Vavilov Int. Conf. «Genetic resources of cultivated plants in the XXI century. Status, problems, prospects»]. St. Petersburg, 2007: 476-477 (in Russ.).

21. Stojałowski S., Myskow B., Hanek M. Phenotypic effect and chromosomal localization of Ddw3, the dominant dwarfing gene in rye (Secale cereale L.). Euphytica, 2015, 201(1): 43-52 (doi: 10.1007/s10681-014-1173-6).

22. Hackauf B., Goldfisch M., Musmann D., Melz G., Wehling P. Evaluation of the dominant dwarfing gene $D d w 1$ with respect to its use in hybrid rye breeding. Tagung der Vereinigung der Pflanzenzüchter und Saatgutkaufleute Österreichs, 2013, 63: 41-42.

23. Kobylyanskii V.D., Solodukhina O.V. Trudy po prikladnoi botanike, genetike i selektsii, 2012, 169: 53-64 (in Russ.).

24. Wolski T., Gryka J. Semidwarf winter triticale. Triticale today and tomorrow. H. Guedes-Pinto, N. Darvey, V.P. Carnide (eds.). Kluwer Academic Publishers, Dordrecht Boston London, 1996: 581-588.

25. Pojmaj M.S., Wolski T. Breeding strategies for improving lodging resistance in winter triticale in connection with heterosis. CIMMYT, 1991. Available http://agris.fao.org/agrissearch/search.do? recordID=QY9200132. No date.

26. Ittu G., Saulescu N.N., Ittu M., Mustatea P. Introduction of short straw genes in Romanian triticale germplasm. Romanian Agricultural Research, 2007, 24: 7-10.

27. Banaszak Z. Breeding of triticale in DANKO. Tagung der Vereinigung der Pflanzenzüchter und Saatgutkaufleute Österreichs, 2010, 61: 65-68.

28. Korshunova A.D., Divashuk M.G., Soloviev A.A., Karlov G.I. Analysis of wheat and rye semidwarfing gene distribution in spring hexaploid triticale (Triticosecale Wittm.) cultivars and breeding lines. Russian Journal of Genetics, 2015, 51(3): 272-277 (doi: 10.1134/s1022795415030072). 
29. Korshunova A.D., Divashuk M.G., Karlov G.I., Solov'ev A.A. Izvestiya TSKHA, 2014, 6: 5-14 (in Russ.).

30. Bazhenov M.S., Divashuk M.G., Krupin P.Yu., Pylnev V.V., Karlov G.I. The effect of 2D (2R) substitution on the agronomical traits of winter triticale in early generations of two connected crosses. Cereal Research Communications, 2015, 43(3): 504-514 (doi: 10.1556/0806.43.2015.002).

31. Thomas S.G. Novel Rht-1 dwarfing genes: tools for wheat breeding and dissecting the function of DELLA proteins. Journal of Experimental Botany, 2017, 68(3): 354-358 (doi: 10.1093/jxb/erw509).

32. Bernatzky R., Tanksley S.D. Genetics of actin-related sequences in tomato. Theoretical and Applied Genetics, 1986, 72(3): 314-321 (doi: 10.1007/BF00288567).

33. Ellis M., Spielmeyer W., Gale K., Rebetzke G., Richards R. "Perfect" markers for the Rht-B1b and RhtD1b dwarfing genes in wheat. Theoretical and Applied Genetics, 2002, 105: 1038-1042 (doi: 10.1007/s00122-002-1048-4).

34. Tenhola-Roininen T., Tanhuanpää P. Tagging the dwarfing gene $D d w 1$ in a rye population derived from doubled haploid parents. Euphytica, 2010, 172(3): 303-312 (doi: 10.1007/s10681009-9982-8).

35. Smiryaev A.V., Kil'chevskii A.V. Genetika populyatsii $i$ kolichestvennykh priznakov [Genetics of populations and quantitative traits]. Moscow, 2007 (in Russ.).

36. Kovtunenko V.Ya., Timofeev V.B., Dudka L.F., Panchenko V.V. Selektsiya i nasinnitstvo, 2008, 96: 89-97 (in Russ.)

37. Pinkal' A.V. Omskii nauchnyi vestnik, 2012, 2 (114): 167-172 (in Russ.).

38. Gol'dvarg B.A., Gritsienko V.G., Boraeva L.N. Sbornik nauchnykh trudov Vserossiiskogo nauchno-issledovatel'skogo instituta ovtsevodstva i kozovodstva, 2007, 2(2-2): 124-128 (in Russ.).

39. Innovatsionnye sorta i tekhnologii vozdelyvaniya yarovogo tritikale: kollektivnaya monografiya [Innovative varieties and technologies for spring triticale cultivation: a collective monograph]. Vladimir, 2017 (in Russ.).

40. Gale M.D., Salter A.M., Angus F.J. The effect of dwarfing genes on the expression of heterosis for grain yield in $\mathrm{F}_{1}$ hybrid wheat. In: Current options for cereal improvement. M. Maluszynski (ed.). Kluwer Academic, Dordrecht, 1989: 49-62.

41. Keyes G., Sorrells M. Rht 1 and Rht 2 semidwarf genes effect on hybrid vigor and agronomic traits of wheat. Crop Science, 1989, 29: 1442-1447 (doi: 10.2135/cropsci1989.0011183X002900060023x).

42. Flintham E., Borner A., Worland A., Gale M. Optimizing wheat grain yield effects of Rht (gibberellin-insensitive) dwarfing genes. The Journal of Agricultural Science, 1997, 128: 11-25 (doi: 10.1017/S0021859696003942).

43. Flintham J.E., Gale M.D. Plant height and yield components of inbred isogenic and $\mathrm{F}_{1}$ hybrid dwarf wheat. Journal of Applied Genetics, 1998, 39: 73-83.

44. Gale M.D., Youssefian S. Dwarfing genes in wheat. In: Progress in plant breeding. G.E. Russel (ed.). Butterworths and Co., London, 1985, V. 1: 1-35.

45. Li X., Lan S., Liu Y., Gale M., Worland T. Effects of different Rht-B1b, Rht-D1b and RhtB1c dwarfing genes on agronomic characteristics in wheat. Cereal Research Communications, 2006, 34(2-3): 919-924 (doi: 10.1556/CRC.34.2006.2-3.220).

46. Chebotar G., Motsnyy I., Chebotar S., Sivolap Y. Effects of dwarfing genes on the genetic background of wheat varieties in Southern Ukraine. Cytology and Genetics, 2012, 46(6): 366-372 (doi: 10.3103/S0095452712060023).

47. Hu Y.G. Utilization of dwarfing genes to improve drought tolerance and yield potential in wheat, 2012. Available http://www.ub.edu/optichinagriculture/data/uploads/workshop2/presentations/huyin-gang-nwaandfu.pdf. Accessed 20.04.2018.

48. Miralles D.J., Katz S.D., Colloca A., Slafer G.A. Floret development in near isogenic wheat lines differing in plant height. Field Crops Research, 1998, 59(1): 21-30 (doi: 10.1016/S03784290(98)00103-8).

49. Miralles D.J., Slafer G.A. Individual grain weight responses to genetic reduction in culm length in wheat as affected by source-sink manipulations. Field Crops Research, 1995, 43 (2-3): 55-66 (doi: 10.1016/0378-4290(95)00041-N). 